\title{
A Dinâmica Inflacionária no New Consensus Economics: uma Análise Crítica
}

\section{The Inflationary Dynamics in the New Consensus Economics: a Critical Analysis}

\author{
Maria Isabel Busato \\ Ricardo Ramalhete Moreira ${ }^{2}$ \\ André Cavalcanti ${ }^{3}$
}

\begin{abstract}
Resumo: A formação de "novos consensos" no campo teórico da economia, tal como o "new Keynesian economics" ou "new neoclassical synthesis", serve hoje de base teórica para a adoção (ou não) de políticas macroeconômicas, tais como os sistemas de metas para a inflação (Inflation Targeting). Este artigo busca apresentar os elementos centrais deste modelo dominante, tanto nos meios acadêmicos como nas práticas dos policy makers, denominado new consensus economics, bem como realizar uma análise crítica das três hipóteses centrais que estão por trás desta formulação e que são utilizadas para racionalizar as proposições do modelo. São elas: (I) a curva de Phillips é estimada com a imposição de neutralidade da moeda no longo prazo; (II) a trajetória do produto potencial é independente das condições de demanda, sendo determinado, no longo prazo, pelas condições de oferta; (III) os choques de oferta são captados pelo componente estocástico. Mostraremos que a dinâmica inflacionária - e o risco iminente de hiperinflação - pode ser muito distinta daquela sugerida pelo "novo consenso" se tais hipóteses forem quebradas.
\end{abstract}

Palavras-chave: Novo consenso. Metas de inflação. Curva de Phillips.

Abstract: The building of new consensus in the theoric arena of economics, such as the "new keynesian economics" or "new neoclassical synthesis", serves nowadays as a theoric base to the adoption of macroeconomic policies, such as inflation targeting regimes. The article aims to present the central elements of a mainstream model, called "new consensus economics", as well as make a critical analysis of its fundamental assumptions: I) the Phillips curve is estimated

1 Professora Assistente do Curso de Economia da Universidade Federal Rural do Rio de Janeiro, Unidade de Três Rios; Doutoranda em Economia pela Universidade Federal do Rio de Janeiro (IE/UFRJ).E-mail: mariaisabelbusato@yahoo.com.br

2 Professor do Departamento de Economia da UFES. E-mail: ramalhete.s@gmail.com

3 Doutorando em Economia pela Universidade Federal do Rio de Janeiro (IE/UFRJ); Analista da Coordenação de Contas Nacionais da Diretoria de Pesquisas do IBGE. E-mail: andrearturcv@ gmail.com. As opiniões expressas neste artigo são de exclusiva responsabilidade de seus autores e não refletem, necessariamente, o ponto de vista das instituições citadas. 
with the assumption of money neutrality in the long run; II) the trajectory of the potential product is independent of demand conditions; III) the supply shocks are expressed by the stochastic component. We will show that the inflationary dynamic - and the imminent hyperinflation risk - may be distinct of that one proposed by the new consensus, if its assumptions are broken.

Keywords: New consensus. Inflation targeting. Phillips curve.

JEL Classification: E31; E58.

\section{Introdução}

A formação de consensos neoliberais na esfera pública, como aqueles que postulam a ineficácia da intervenção do Estado nos mercados, veio acompanhada da formação de "novos consensos" também no campo teórico da economia, como a "new Keynesian economics" ou "new neoclassical synthesis", que hoje serve de base teórica para a implementação de políticas macroeconômicas, tais como os sistemas de metas de inflação (Inflation Targeting), adotados numa série de países a partir dos anos 90. Ao buscar fundamentos microeconômicos para a rigidez de preços sem abandonar teoricamente a hipótese de expectativas racionais ${ }^{4}$ e a teoria do emprego neoclássica, o "novo consenso" mantém como pilar fundamental de suas formulações o princípio de que a dinâmica do produto independe das condições de demanda (ao menos no longo prazo). Além disso, a manutenção da hipótese neoclássica de que a oferta possui uma trajetória de longo prazo determinada à la Solow, resulta na ideia de que a origem da inflação persistente estaria do lado da demanda, dado que qualquer demanda adicional imposta à economia acima daquela sancionada pelas condições da oferta teria efeitos inflacionários. $\mathrm{O}$ efeito prático de tais pressupostos é que restaria aos Bancos Centrais a exclusiva tarefa de perseguir o controle inflacionário, deixando que os "outros mecanismos" resolvam eventuais problemas nas esferas reais da economia, como a estabilização do produto e do emprego.

Diante disso, este artigo pretende apresentar os elementos centrais do modelo hoje dominante, tanto nos meios acadêmicos como nas práticas dos policy makers, denominado new consensus economics, bem como realizar uma análise crítica de um dos suportes utilizados para racionalizar as proposições do modelo, qual seja, a imposição de que existe uma curva de Phillips aceleracionista, e vertical no longo prazo (i.e. no longo prazo não existiria trade-off entre inflação e desemprego).

Além desta introdução, apresentaremos, na primeira seção, os elementos teóricos centrais da nova síntese. Na segunda seção mostraremos

Na prática, porém, observam-se a adoção de modelos com formulações hỉbridas de expectativas. 
que as proposições do new consensus podem ser racionalizadas a partir de três equações básicas: uma função IS, uma curva de Phillips - sobre a qual é imposta a condição de verticalidade no longo prazo - e uma regra de reação de juros (variante da regra de Taylor). Mais especificamente, busca-se realizar uma análise crítica das hipóteses impostas aos parâmetros da curva de Phillips, mostrando-se que os resultados mudam radicalmente se forem quebradas tais hipóteses. Por fim, alguns comentários finais serão feitos, à guisa de conclusões.

\section{Um "Novo Consenso": os Elementos Centrais}

O "novo consenso", conhecido também como new Keynesian economics (new neoclassical synthesis / new consensus approach) ${ }^{5}$ representa hoje um guia fundamental de boa parte dos Bancos Centrais na configuração de suas políticas monetárias, tal como os sistemas de metas para a inflação (ARESTIS, 2003). A adoção de sistemas de metas para a inflação é o elemento central do conjunto de prescrições (ou não) de políticas econômicas sugeridas por essa corrente, cuja matriz teórica teve, a partir principalmente dos anos 80 , um enorme poder de penetração tanto na academia como nas práticas de política macroeconômica, sendo inclusive hoje reconhecidamente o mainstream da macroeconomia. Na verdade, autores tais como Romer (2000), Blinder (1988) e Taylor (1997; 2000) não abandonam a necessidade - sugerida pela "primeira linhagem" de novoskeynesianos - de dar microfundamentos à macroeconomia. No entanto, nos trabalhos acima referenciados eles deixam de lado a necessidade da excessiva formalização que esses modelos requerem e fazem um apelo para uma análise da economia de maneira visivelmente "simples" e, portanto, muito atraente, pois são aparentemente mais realistas.

A contribuição feita por essa corrente teórica na discussão sobre a curva de Phillips - seu possível formato e determinantes - foi uma tentativa de dar uma dose de realismo à tal formulação, incluindo choques de custos - que alterariam os preços relativos - além das expectativas inflacionárias e do desvio do desemprego de sua trajetória natural, para explicar a inflação (SERRANO, 2006). A inclusão desse elemento teria sido uma tentativa de chamar a atenção para o fato de que um processo inflacionário poderia ser deflagrado por choques de oferta tais como quebra de safras, cartelização, variações cambiais entre outros fatores que são de grande relevância para explicar o movimento dos preços. Além disso, eles introduziram uma mudança importante quanto à variá-

5 Segundo Taylor (2000, p. 90), essa nova abordagem tem sido designada por vários nomes, tais como, new Keynesian economics, new neoclassical synthesis e new consensus approach. 
vel de controle da autoridade monetária. Na tradição macroeconômica, desde o modelo IS-LM, passando pelo monetarismo e pelos novos clássicos, tinha-se a ideia de que a autoridade monetária tentaria controlar algum dos agregados monetários. A nova síntese abandona esta ideia. Assume que a moeda é endógena e rejeita a hipótese de que a oferta de moeda seja variável de controle da autoridade monetária, já que os Bancos Centrais são incapazes de controlá-la (ROMER, 2000, p. 25).

O realismo que parece estar presente em seus trabalhos os tornou muito aceitos no meio acadêmico e nas práticas de "política econômica", tanto que boa parte dos Bancos Centrais de países que adotam o sistema de metas para a inflação utiliza esta matriz teórica.

Com base em Taylor (2000, p. 90) - um dos expoentes dessa corrente ${ }^{6}$ - pode-se traduzir as ideias do new consensus approach a partir de cinco pilares centrais, a saber:

I) a trajetória do produto potencial (de longo prazo) independe das condições de demanda, sendo determinado, pelas condições de oferta. Ademais, a dinâmica de crescimento da economia é explicada pelo modelo de crescimento de Solow estendido - uma tentativa de incorporar endogenamente a tecnologia - (modelo de crescimento endógeno);

II) existe, no curto prazo, um trade-off entre inflação e desemprego; contudo, no longo prazo, as políticas de estimulo à demanda são neutras, o que resulta na verticalidade da curva de Phillips no longo prazo;

III) a existência do trade-off entre inflação e desemprego é fruto, sobretudo, da rigidez temporária dos preços e salários, e implica significativamente nas flutuações do produto/emprego real em torno do produto potencial/natural;

IV) as expectativas inflacionárias são endógenas;

V) as decisões de política monetária deveriam seguir regras claras, na qual a taxa de juros nominal, de curto prazo, é ajustada em reação aos eventos econômicos.

Para Taylor (2000, p. 90), o new consensus approach teria sido o resultado do processo evolutivo gradual da macroeconomia originária da revolução macroeconômica das expectativas racionais desenvolvida pelos novo-clássicos durante a década de 1970. Nesse contexto, esse "novo consenso" é mais uma tentativa de (micro)fundamentar a macroeconomia, admite competição imperfeita e assume que a existência de rigidez de preços e salários pode ser derivada do comportamento racional e maximizante dos agentes (ROMER, 1993, p. 7).

Desse modo, o novo consenso busca dar fundamentos microeconômicos à rigidez de preços sem abandonar a hipótese de expectativas racionais

$6 \quad$ Além de Taylor, essa corrente tem como autores Ben Bernanke, David Romer, Blinder, Gordon, Mankiw, entre outros. 
$(\mathrm{HER})^{7}$ e a teoria do emprego neoclássica. Segundo Gordon (1990, p. 1137), "[...] the development of new-Keynesian economics [...] involved the search for rigorous and convincing models of wage and/or price stickiness based on maximizing behavior and rational expectation". Dar micro fundamentos à rigidez de preços significa, por sua vez, compreender as "rigidezes" a partir do comportamento do agente representativo maximizador; essa abordagem recusa, porém, a possibilidade de interpretar a realidade econômica a partir de mercados perfeitos que se equilibrariam, de maneira imediata, via preços (market-clearing). ${ }^{8}$ A presença de rigidez nominal e real de preços e salários explicaria os desvios do produto e do emprego de suas trajetórias naturais, implicando, inclusive, na quebra da dicotomia clássica e na existência de trade-off entre inflação e desemprego no curto prazo ${ }^{9}$ (MANKIW, 1988, p. 439).

A existência dessas falhas criaria uma instabilidade relativa do equilíbrio, impedindo temporariamente que o processo de ajuste entre oferta e demanda conduzisse ao pleno emprego da força de trabalho, justificando, por sua vez, a existência do desemprego involuntário. Contudo, no longo prazo, após o ajustamento de preços e salários, prevaleceria (a) a estabilidade clássica ou novo-clássica com uma taxa natural de desemprego; (b) o produto em seu nível potencial; e (c) a verticalidade da curva de Phillips. Isso posto, identificamos/justificamos os primeiros três pilares que traduzem as ideias propostas pelo novo consenso.

Mais especificamente, o primeiro pilar contém a ideia de que a dinâmica do produto independe das condições de demanda, ou seja, existe um "[...] level of production it can achieve with existing labor, capital, and technology without putting sustained upward pressure on inflation"10 (LE HERON, 2003, p. 5). No entanto, a presença de rigidezes (terceiro postulado) faz com que exista, no curto prazo, trade-off entre inflação e desemprego. Em outras palavras, o segundo pilar nos diz que os autores do novo consenso defendem a existência de uma curva de Phillips negativamente inclinada no curto prazo, de tal modo que, nesse horizonte de tempo, a demanda não é completamente passiva. Contudo, no longo prazo, as políticas de estímulo à demanda são neutras, caracterizando a existência da verticalidade da curva de Phillips. De fato, a literatura convencional

\footnotetext{
7 Ressalta-se, porém, que autores tais como Mankiw e Romer desenvolveram uma série de modelos sem entrar a fundo na questão das expectativas racionais.

8 Como proposto pelos novos clássicos.

9 Mankiw argumenta que "na visão novo-keynesiana 'as flutuações na demanda agregada afetam a produção e o emprego apenas no curto prazo', e de que 'no longo prazo a economia retorna para os níveis de produção e emprego e desemprego descritos pelo 'modelo clássico'” (MANKIW; ROMER, 1989, p. 1-2).

10 Nível de produção associado a uma taxa de desemprego "natural", freqüentemente denominada Non-Accelerating Inflation Rate of Unemployment (NAIRU).
} 
sobre credibilidade e reputação da autoridade monetária busca mostrar que, na ausência de mecanismos de compromisso (commitment mechanisms) da política monetária, haveria um viés inflacionário decorrente da inconsistência temporal na condução da mesma pelo Banco Central. No entanto, devido ao fato de que os agentes conhecem os estímulos e motivações da autoridade monetária, no longo prazo, políticas expansionistas resultariam em excesso inflacionário, sem que houvesse qualquer benefício em termos de nível de atividade econômica (BARRO; GORDON, 1983).

$\mathrm{O}$ quarto pilar diz respeito à forma como os agentes formam suas expectativas. O novo consenso admite, como dissemos, que os agentes formam suas expectativas racionalmente. A HER assegura que os agentes deixariam de ser backward-looking, passando à condição de forwardlooking (as decisões tomadas no presente dependem não somente dos estados passado e atual do ambiente econômico, mas também de um completo portfólio de eventos esperados), não cometendo, portanto, erros serialmente correlacionados. Ademais, ao utilizar o conceito de esperança condicional como proxy de formação de expectativas, é garantido que os agentes utilizam o mais eficiente estimador linear não-viesado à sua disposição. Conceitualmente, as expectativas dos agentes "[...] são ditas serem racionais se elas dependem, de maneira apropriada, das mesmas coisas que a teoria econômica diz determinar atualmente aquela variável" (MUTH, apud BARBOSA, 1990, p. 153). Logo, ao adotar a HER os agentes conhecem as probabilidades da ocorrência dos eventos e as expectativas subjetivas dos indivíduos coincidem com o valor de sua esperança matemática da variável futura condicionada a todas as informações e demais variáveis do modelo. Ao formularem suas expectativas sobre o futuro, os agentes econômicos - racionais e otimizadores - acabariam por determinar os preços presentes (TOWNSEND apud KLAMER, 1988, p. 89).

Nesse ponto cabe chamarmos a atenção para o fato de que, como descrito no quarto pilar, as expectativas são supostas endógenas, ou seja, elas são racionais e incorporam os erros cometidos. Desse modo, ressaltase que nessa teoria não cabem erros sistemáticos, haja vista a hipótese de "aprendizado" subjacente à HER. Por hora não nos deteremos em dar explicações sobre a necessidade e as implicações dessa hipótese, que será mais bem compreendida no decorrer do texto.

Por fim, resta-nos fazer algumas considerações a respeito do quinto pilar da nova síntese. Dada a rigidez de preços e salários, os "new Keynesian" admitem, no curto prazo, o ativo papel da demanda agregada na determinação do produto, bem como a efetividade da política monetária em afetar o produto. Essa política, para Taylor (2000), deveria seguir regras claras. Demais adeptos da nova síntese advogam que esse tipo de política deveria ser interpretado como algo além da simples adoção de 
regras; na verdade, ele seria estruturado muito mais como um sistema de política (Sistema de Metas de Inflação). Para Bernanke e Mishkin (1997, p. 98), o sistema de metas de inflação, principal política prescritiva do "novo consenso",

[...] does not represent an ironclad policy rule [...] instead, inflation targeting is better understood as a policy framework, whose major advantage is increased transparency and coherence of policy, and in which fairly flexible, even 'discretionary' monetary policy actions can be accommodated.

No entanto, o argumento de que o sistema de metas não representaria uma "regra rígida de política" nos parece estranho, pois as propriedades de longo prazo do sistema econômico, assumidas a priori, não dão margem de manobra para que a política econômica seja interpretada/conduzida de outra forma senão pelo necessário estabelecimento de regras para a atuação do BC (Banco Central), ainda que não seja uma regra rígida como a proposta por Friedman (1978) ${ }^{11}$ Na verdade, como o próprio Bernanke et al. (2001) afirmou, o argumento para a adoção do regime de metas para conter a inflação pode ser resumido em dois pontos centrais, a saber: I) no longo prazo, a única variável que pode ser afetada pela política monetária é a taxa de inflação; II) taxas moderadas de inflação são importantes para o crescimento e a eficiência econômica devendo, portanto, constituir o objetivo de longo prazo dos policy-makers. Diante dessas hipóteses não restaria aos formuladores de política monetária outra opção senão a de perseguir somente o controle inflacionário. O regime de metas de inflação, tal como concebido por Bernanke e Mishkin (1997), seria um instrumental de política monetária que, ao conduzir a uma maior transparência e credibilidade da atuação da autoridade monetária, facilitaria o alcance da estabilidade de preços no longo prazo, expressa pelas metas de inflação anunciadas. Entretanto, esses autores querem mostrar que no âmbito do regime de metas, ao menos em teoria, existiria espaço considerável para que a política monetária tenha uma função contracíclica no curto prazo, levando em consideração questões relacionadas ao produto e taxa de câmbio, por exemplo.

Diante de choques de oferta, o Banco Central não estaria "preso" às metas de inflação, pelo que não seria necessário impor à economia perdas de produto; através de "cláusulas de escape", ou através da utilização de índices de preços que expurgam variações em preços de energia e alimen-

11 Para Friedman $(1963 ; 1978)$, a intervenção deveria ser conduzida em termos de regras estáveis. Isso quer dizer que a política monetária deveria ser pautada por uma "política monetária adequada”, que fixasse regras de política estruturadas a partir de uma taxa de crescimento constante para a oferta monetária, buscando estabilizar as expectativas dos agentes. 
tos (núcleo da inflação), ou ainda pela adoção de bandas ao invés de uma meta pontual, o Banco Central poderia acomodar o desvio inflacionário no curto prazo (medido pelo índice cheio), evitando a necessidade de se aumentar as taxas de juros e reduzir o produto. Neste sentido, o regime não poderia ser associado a uma "regra cega" de política, tal como no sentido friedmaniano. Uma regra à la Friedman seria a adoção de uma taxa de crescimento rígida para os agregados monetários ou a adoção exclusiva de uma única taxa de juros (natural), independentemente do que esteja acontecendo na conjuntura econômica. Por outro lado, o regime de metas de inflação poderia receber diferentes configurações e instituições monetárias a partir das diferentes preferências sociais de cada país ou economia. O grau de flexibilidade do regime de metas iria depender do peso que o Banco Central dê à estabilização do produto vis-à-vis a estabilização da inflação (SVENSSON, 1997).

No entanto, as preocupações com a estabilização do produto, quando existem, no regime de metas, particularmente o do Brasil, estão restritas ao curto prazo. O regime de metas de inflação tem como um de seus elementos fundamentais o fato de que o objetivo precípuo da política monetária no longo prazo é a estabilidade de preços e que eventuais outros objetivos de política são subordinados a ele. ${ }^{12}$ Qualquer intento ou atuação contra-cíclica de curto prazo por parte do Banco Central não deveria colocar em risco o alcance e manutenção da estabilidade de preços no longo prazo. Já que, segundo Svensson (1998), o regime de metas de inflação tem como um de seus fundamentos a "hipótese da taxa natural", ou seja, a hipótese de que no longo prazo a política monetária é incapaz de afetar o produto nem a taxa de desemprego. No longo prazo, ambas as variáveis convergem para seus valores naturais ou potenciais, sendo essa convergência garantida pelo funcionamento dos mercados, independentemente de qual seja a regra de política monetária. Logo, o regime de metas não escolhe o produto potencial em torno do qual o BC vai estabilizar o produto. O produto potencial é dado, existindo apenas a escolha de uma meta de inflação no longo prazo. Um dos objetivos desse trabalho é analisar o relaxamento dessa hipótese - analisar a possibilidade de correlação entre produto e moeda no longo prazo - e suas consequências para a política monetária em geral, e para o regime de metas de inflação em particular.

Se for verdade que o produto tende para a sua trajetória natural caracterizando a passividade da demanda em sua determinação - e se o controle inflacionário promove a eficiência econômica estimulando novos

12 Mishkin (2000, p. 2), por exemplo, é bastante claro nesse sentido ao defender que os sistemas de metas englobam "an institucional commitment to price stability as the primary goal of monetary policy, to which other goals are subordinated". 
investimentos e o crescimento econômico, restaria ao Banco Central (apenas) perseguir o controle inflacionário, ou alcançar uma meta de inflação no longo prazo, e deixar que os "mecanismos endógenos", de mercado, resolvam as demais questões macroeconômicas. Desse modo, entendemos que ao fixar metas objetivas para a inflação e ao canalizar todos os esforços para que tal objetivo seja atingido, a política monetária pode sim ser entendida como uma regra de atuação. ${ }^{13}$ De fato, Svensson (1997; 1998) vai definir o regime de metas de inflação como uma "regra de política monetária", na qual são especificados valores ou níveis desejados para a inflação (meta de inflação) e para o produto (potencial), cujo alcance vai minimizar o que se chamaria de função perda social. Ainda que haja espaço relativo para discricionariedade no ajuste das taxas de juros, tal ajuste seria feito de forma a permitir o alcance das metas e a consequente minimização da chamada "função perda". Em outras palavras, ainda que o regime de metas não estipulasse necessariamente uma atuação mecânica e única para a resposta das taxas de juros de curto prazo, essa resposta está condicionada ao alcance ou satisfação das metas para a inflação adotada. Portanto, o regime de metas não compromete o $\mathrm{BC}$ com uma forma única e irrevogável de resposta ou reação para a taxa de juros, mas o compromete com o alcance de metas: uma meta escolhida, a inflação de longo prazo, e uma meta dada, o produto potencial. Novamente, o presente trabalho analisará os resultados teóricos que decorrem da contestação da ideia de que o produto está dado no longo prazo. Tal contestação parte da ideia básica de que existe path-dependence no produto, ou seja, de que o produto de curto prazo afeta de alguma maneira o produto de longo prazo. Assim, uma vez que a política monetária afeta diretamente o produto de curto prazo, ela também afeta, ainda que indiretamente, o produto de longo prazo.

\section{A Racionalização das Proposições do New Consensus}

Inúmeras têm sido as tentativas - com maior ou menor grau de sofisticação - de sumarizar as proposições do new consensus em um grupo de modelos estruturais que captaria os supostos mecanismos de transmissão da política monetária. Dentre as quais, podemos citar Bogdanski et al. (2000); Clarida, Gali e Gertler (1999) e em Meyer (2001). Neste trabalho iremos utilizar - com algumas modificações - a abordagem proposta por Bogdanski et al. (2000) que coincide inclusive com aquela sugerida no

13 Autores tais como Kriesler e Lavoie (2005) defendem que é um tanto enigmática a terminologia New Consensus, já que, em grande medida, suas proposições de política monetária representariam um retorno às propostas de Friedman. 
Boletim do Banco Central (BBC) (2000, p. 96). No refererido relatório do Banco Central do Brasil, o uso dessas equações é assim justificada: "o BC vem desenvolvendo e aperfeiçoando um grupo de modelos estruturais para o mecanismo de transmissão da política monetária, cujo objetivo principal é identificar e quantificar o grau de intensidade e as defasagens dos principais canais de transmissão". Canais de transmissão, esses, subjacentes ao modelo teórico proposto por essa "nova" forma de pensar a política econômica, em especial a política monetária.

O arsenal geral sugere o uso de uma curva IS que sumariza o efeito de curto prazo da política monetária sobre o produto e emprego da economia; o uso de uma curva de Phillips que possibilite fazer a previsão da inflação. Se a previsão inflacionária estiver fora da meta estabelecida (incluindo as margens de erro) a autoridade monetária utilizaria uma regra reativa de juros ${ }^{14}$ (por meio de uma regra do tipo Taylor, mas não necessariamente com metas para o produto) - que se torna subordinada aos objetivos de inflação previamente estabelecidos - para fazer com que a inflação retorne para a meta estabelecida. Ou seja, a autoridade monetária estabelece as metas para a inflação e uma via única de combate à elevação da mesma, qual seja, a política de manipulação de juros para, teoricamente, conter pressões de demanda. Esses e outros mecanismos de transmissão macro fazem parte do grupo de equações/modelos estruturais utilizados por diversos autores para expressar as proposições do novo consenso. A relação juros-demanda agregada-inflação pressupõe os seguintes mecanismos de transmissão: I) a demanda agregada (via redução do gap do produto) é a principal responsável pela inflação; II) a taxa de juros é eficiente em comprimir a demanda agregada e, consequentemente, o nível de preços.

O "grupo" de equações/modelos estruturais representativos da nova-síntese e usado para identificar os mecanismos de transmissão da política monetária pode ser tão complicado quanto se desejar, mas, em sua essência, pode ser resumido em três ${ }^{15}$ equações básicas: (I) uma função IS; (II) uma curva de Phillips; e (III) uma regra reativa de juros.

A especificação da curva IS, em sua versão dinâmica, irá expressar o efeito de curto prazo da política monetária sobre o hiato do produto

14 Na adoção prática não se anuncia qual seria essa regra reativa de juros. A manipulação dos juros é discricionária, mas se subordina aos objetivos da meta para a inflação.

15 Tanto no artigo do Bogdanski et al. (2000) como do BBC (2000) há uma quarta equação que estabelece uma condição de paridade descoberta de juros que estabelece o equilíbrio financeiro no mercado cambial. Nela a taxa de juros interna seria igual à taxa de juros externa somada da expectativa de desvalorização cambial e do prêmio de risco doméstico. No entanto, a maioria dos trabalhos negligencia tal equação. Além disso, sua ausência não prejudica nossa análise. 
ou, por assim dizer, sobre o grau de utilização da capacidade. É importante compreender que a curva IS é fundamental para os modelos de metas para a inflação, pois é através dela que se determina o impacto dos juros sobre a demanda e, por conseguinte, sobre o gap do produto, que não deveria acelerar a inflação. A curva IS:

$$
h_{t}=\beta_{0}+\beta_{1} h_{t-1}+\beta_{2} h_{t-2}+\beta_{3} r_{t-1}+e_{t}^{h}
$$

A proposta é especificar a IS de modo que expresse o gap do produto $(h)$ em função das suas próprias defasagens $\left(h_{t-1}\right.$ e $\left.h_{t-2}\right)$; da taxa real de juros $\left(r_{t-1}\right)$ e dos choques de demanda ( $\left.\mathrm{e}_{t}^{\mathrm{h}}\right)$ (componente aleatório). Existem muitas críticas sobre os mecanismos de transmissão sugeridos nessa especificação, no entanto, foge ao nosso objetivo entrar nessa discussão.

Note que nessa especificação dos mecanismos de transmissão da política monetária para o hiato do produto ( $h$, em log), inclui-se a defasagem de um período entre a definição da taxa de juros e seus impactos sobre o hiato do produto. Logo, mesmo que a taxa de juros básica fosse eficaz em alterar a demanda agregada e a produção, levaria algum tempo. Além disso, como se verá adiante, na especificação da curva de Phillips, a inflação também sofre influência do hiato do produto com defasagem de um período, a defasagem total entre o ajuste da taxa de juros e seus impactos sobre a inflação seria, portanto, de dois períodos. Há, dessa maneira, um período de tempo extenso entre as decisões de política e os efeitos da mesma sobre a inflação observada ex post.

Uma vez que o BC não possui controle pleno sobre os determinantes da inflação, e que muitos acontecimentos imprevistos podem ocorrer dentro do "tempo de defasagem", torna-se muito provável que haja diferenças entre a inflação ex post e a meta de inflação estabelecida ex ante. Alguns críticos argumentam que o regime de metas de inflação não seria eficiente porque a inflação observada é uma variável de múltiplos determinantes, muitos dos quais fora de controle do BC, e de correlação muito defasada com a taxa de juros. O BC poderia argumentar que os desvios entre a inflação observada e a meta de inflação foram devidos a elementos ou a perturbações fora de seu controle, imunizando-se das críticas e da responsabilidade pelos desvios inflacionários (Cf. Svensson, 1997). Nesse caso, o próprio modelo de previsão inflacionária utilizado pelo BC deveria ser revisto.

Quanto mais difícil for a mensuração ou monitoração pelo público da eficácia da política monetária, menor será a prestação de contas (accountability) do BC e menor será sua reputação e credibilidade, o que dificultaria, nesse arcabouço teórico, sensivelmente processos de desinflação. 
Por sua vez, a curva de Phillips é um modelo estrutural ${ }^{16}$ utilizado para explicar a inflação como função de sua própria defasagem; ${ }^{17}$ da inflação esperada; do hiato do produto; e de choques de oferta. Nossa insatisfação com a especificação proposta se refere à imposição $a$ priori da hipótese de neutralidade da moeda no longo prazo, resultando em uma curva de Phillips vertical sobre a NAIRU. A curva de Phillips pode ser assim expressa: ${ }^{18}$

$$
\pi_{1}=\alpha_{1} \pi_{t-1}+\alpha_{2} E\left(\pi_{t+1}\right)+\alpha_{3} \pi_{t-2}+\alpha_{4} h_{t-1}+\varepsilon_{t}^{h}
$$

onde:

$\pi=$ é log da inflação;

$h=\mathrm{o} \log$ do hiato do produto;

$\mathrm{E}_{\mathrm{t}}(\cdot)=\mathrm{o}$ operador de expectativas condicionada à informação disponível em t;

$\alpha_{4}=$ mede o impacto de alterações no hiato do produto sobre a inflação.

Note que a inflação passada e a esperada, cujos impactos são captados por $\alpha_{1}$ a $\alpha_{3}$, são argumentos utilizados para explicar a inflação corrente; $\varepsilon_{\mathrm{t}}^{\mathrm{h}}$ representa os choques estocásticos. Na literatura sobre o regime de metas de inflação, quanto maior a credibilidade do BC, maior deveria ser o peso da inflação esperada (componente forward-looking) - que tenderia a ser igual à meta de inflação -, e menor deveria ser o peso da inflação passada (componente backward-looking) na formação e estimação da curva de Phillips (BOGDANSKI et al., 2000).

A curva de Phillips serve, portanto, de guia para mostrar a influência da inflação passada e da esperada, bem como do hiato do produto sobre a inflação corrente. O mecanismo de transmissão da demanda agregada para a inflação pode ser entendido da seguinte forma: "the inflation rate falls when unemploymet is above NAIRU, and increases when unemployment is below it" (KRIESLER; LAVOIE, 2005, p. 2).

Tendo sido sugeridos os mecanismos de transmissão da demanda agregada sobre o hiato do produto e desse, juntamente com as demais

16 Um modelo estrutural é aquele que contém relações teóricas propostas por alguma teoria econômica, ao passo que os não estruturais são os do tipo autorregressivos.

17 O modelo teórico sugere que os agentes formam suas expectativas racionalmente, e que a inclusão de expectativas adaptativas na especificação prática "[...] is vulnerable to the Lucas critique" (BOGDANSKI et al., 2000, p. 21). No entanto, a inclusão de expectativas adaptativas se justificaria “[...] primariamente por motivos empíricos" (BBC, 2000, p. 100). Já Meyer (2001, p. 3) argumenta que a inclusão de expectativas adaptativas se justifica pois "[...] the effect of past inflation captures the role of sticky prices". Na prática, autores tais como Romer (2000) e Taylor (2000) não estão excessivamente preocupados com expectativas racionais.

18 A especificação poderia ser tanto mais complicada como mais simplificada do que essa proposta modificada que estamos retirando de Bogdanski et al. (2000), excluindo os preços externos para simplificar a análise sem causar prejuízos ao argumento deste artigo. 
variáveis, sobre a inflação, verifica-se se essa estará ou não dentro da meta estabelecida. Caso não esteja, a taxa de juros é manipulada para que o "alvo" seja atingido.

Por trás dessa especificação da curva de Phillips existem três hipóteses centrais ${ }^{19}$ que podem ser encontradas tanto em Bodganski et al. (2000, p. 21) e no BBC (2000), quanto nos textos de referências sobre o assunto, já que a imposição de tais hipóteses é comum à racionalização do modelo proposto pela nova síntese. ${ }^{20}$ São elas: (I) a curva de Phillips é estimada com a imposição de que os coeficientes $\alpha$, exceto aquele associado ao hiato do produto somam 1 (unidade) ${ }^{21}$ Isso significa que a equação de Phillips é estimada com uma imposição de neutralidade da moeda no longo prazo, ou, por assim dizer, com a imposição de que, no longo prazo, ela é vertical; ${ }^{22}$ (II) a segunda imposição diz respeito à trajetória do produto potencial de longo prazo. Esse é independente das condições de demanda, sendo determinado, no longo prazo, pelas condições de oferta; (III) os choques de oferta são captados pelo componente estocástico. Estatisticamente supõe-se, em modelos econométricos, que tais erros têm esperança matemática igual a zero. Ou seja, choques positivos e negativos se compensam ao longo do tempo.

A justificativa teórica para a imposição das primeiras duas hipóteses foi assim expressa por Bogdanski et al. (2000):

[...] is fundamental to explain clearly [...] the goals and limitations of monetary policy (what the Central Bank can do in the long run is to control inflation; what it cannot do is to raise economic growth through monetary expansion). ${ }^{23}$

Essas duas hipóteses implicam, em temos de política, na ineficácia dessa em afetar, ao menos no longo prazo, as variáveis reais da economia, sendo a expansão monetária responsável pelo nível de preços.

19 As duas primeiras hipóteses são explicitadas no relatório do Banco Central (2000) e no artigo de Bodganski et al. (2001), os quais apresentam argumentos teóricos para tal adoção. A terceira, no entanto, é uma hipótese implícita, ou seja, na formulação da equação de Phillips os choques de oferta seriam captados pelo componente aleatório, com média zero e variância constante, implicando que choques positivos e negativos tendem a se autoanular. Não há explicação teórica explicita para tanto.

20 Ver também Serrano (2006).

21 No artigo original de Bodganski et al. (2000, p. 21) ele afirmou que os coeficientes alfa somam 1 , exceto o associado ao hiato do produto. Em nossa versão estamos excluindo a aceleração do câmbio e, portanto, apenas os coeficientes associados a inflação defasada e esperada somam 1 .

22 Conforme o BC (2000, p. 96) e Bogdanski et al. (2000, p. 21) supõe-se a existência de mecanismos endógenos que levariam a economia para "a taxa natural" de desemprego.

23 Dentro do arcabouço teórico do new consensus, Mishkin (2000, p. 3) reafirma a incapacidade da política monetária em afetar o produto: "inflation targeting has the advantage of focusing the political debate on what a central bank can do in the long run - i.e., control inflation - rather then it cannot do - raise output growth, lower unemployment, increase external competitiveness - through monetary policy" (MISHKIN, 2000, p. 3). 
A imposição de full inertia tem uma especial implicação em termos de política econômica, pois a partir dessa imposição surge a seguinte questão: excesso de demanda causa inflação, aceleração inflacionária ou aumento do nível de preços? Ou ainda, qual é o papel da inflação ocorrida e da esperada sobre a inflação corrente?

Estamos chamando de inércia completa (full inertia) a imposição de que a soma dos coeficientes associados aos lags e à expectativa de inflação somam 1. Na equação, a soma dos alfas (exceto alfa 4) deve ser igual a 1 para ser consistente com a hipótese de neutralidade no longo prazo. A adoção dessa hipótese - inércia completa ${ }^{24}$-implica que choques temporários nos preços (por exemplo, um choque de oferta em um único período), gerariam um aumento na inflação, de modo que a economia conviveria com uma taxa de inflação constante, mas permanentemente mais elevada (HADJIMICHALAKIS, 1982, p. 356). Além disto, ainda que temporário, um choque inflacionário resultaria num nível de inflação permanentemente mais elevado e num nível de produto apenas temporariamente mais elevado. Por outro lado, um aumento na taxa de expansão monetária, ${ }^{25}$ que expandisse a demanda agregada e aumentasse o grau de utilização, para além do produto potencial, jamais teria seus efeitos dissipados, gerando aceleração contínua da inflação. Ou seja, sob inércia completa os choques inflacionários seriam altamente persistentes, podendo levar a economia para a hiperinflação. Desse modo, a "inflation is postulated to accelerate if unemployment is held below the NAIRU" (ARESTIS, 2003, p. 8), já que no longo prazo inexiste trade-off entre inflação e desemprego.

Além da imposição de inércia completa, para que a dinâmica inflacionária seja a descrita acima é preciso que a inflação esperada seja ao menos parcialmente endógena - "v pilar" descrito na seção anterior. Ou seja, os agentes aprendem com os erros cometidos (processo de aprendizado). Alternativamente, pode-se dizer que, mesmo sob alta credibilidade do $\mathrm{BC}$, os agentes não iriam insistir em uma expectativa inflacionária divergente - período a período - da inflação ocorrida. ${ }^{26} \mathrm{Ou}$, por assim dizer, "[...] if the price level rises gradually after the increase in the money stock, the increase raises expected inflation" (ROMER, 2000, p. 23).

24 Ressalta-se, no entanto, que trabalhos econométricos tais como Campêlo e Cribari-Neto (2003) não concluíram em favor da inércia completa para o caso brasileiro. Ao contrário, o trabalho encontrou um baixo grau de inércia para a inflação brasileira.

25 Resultado equivalente seria obtido se supuséssemos uma queda na taxa de juros para aquém da "taxa natural" de juros à la Wicksell.

26 Em um artigo dos anos 80, Lopes faz a seguinte afirmativa ao tentar explicar a persistência de processos inflacionários: "[...] a tendência em termos da inércia inflacionária [...] resulta de um padrão rígido de comportamento dos agentes econômicos em economias cronicamente inflacionadas" e continua: "[...] a inflação corrente é determinada pela inflação passada" (LOPES, 1985, p. 136). 
Assim, ao se utilizar, na formulação da curva de Phillips, a HER, ainda que sob uma combinação híbrida (expectativas adaptativas + expectativas racionais) necessita-se de uma hipótese adicional sobre as expectativas (racionais) dos agentes, qual seja, as expectativas devem ser endógenas. Essa hipótese pode parecer irrelevante, mas é de extrema importância, pois se tais expectativas não se ajustassem à trajetória corrente do nível geral de preços, a hipótese de inércia completa poderia ser quebrada. Imagine-se que os agentes possuam uma expectativa de inflação menor que a efetiva. Se eles não mudam suas expectativas, errando período a período (uma situação de super credibilidade do BC), mesmo diante de choques de inflação, essa convergiria mais ou menos rapidamente (de acordo com o valor do parâmetro associado à expectativa condicional (racional), para o valor "desejado" da taxa de inflação. ${ }^{27}$

Desse modo, na equação de Phillips adotada pelo BC, a única maneira da inflação não explodir, diante de persistentes "excessos de demanda" seria considerarmos que as expectativas racionais dos agentes não são de fato racionais. Ou seja, sugerindo que a inflação esperada fosse exógena e não se ajustasse ante as mudanças na inflação corrente.

Tendo feito tais considerações, supondo então inércia completa, com endogeneidade das expectativas, podemos extrair do modelo o fato de que a persistência do governo de expandir a demanda, reduzindo o desemprego "abaixo da taxa natural", faria com que a inflação explodisse (acelerasse incessantemente). Esse resultado acaba sendo uma justificativa muito relevante em prol do não ativismo.

A hipótese de inflação inercial, amplamente disseminada no Brasil nos anos 80 tem sua versão radicalizada. Nos anos 80 a ideia de inércia se aplicava no caso em que:

[...] num ambiente cronicamente inflacionário, os agentes econômicos desenvolvem um comportamento fortemente defensivo na formação de preços [de tal modo que] a taxa de inflação existente no sistema tende a ser perpetuar: a tendência inflacionária torna-se igual à inflação passada. (LOPES, 1985, p.137, grifo nosso).

Assim, até mesmo os adeptos da ideia de inflação inercial admitiam inércia completa somente nos casos extremos em que havia um ambiente cronicamente inflacionário, levando os agentes a desenvolverem comportamentos defensivos. ${ }^{28}$

27 No caso de super credibilidade do $\mathrm{BC}$ e se o coeficiente associado à HER for igual à unidade.

28 Simonsen (1970, p. 129, grifo nosso) ao descrever os fatores explicativos da taxa de inflação, inclui um componente denominado de retroalimentação (inércia). Sobre o parâmetro associado a tal componente, ele afirmou: "o parâmetro b, que será denominado coeficiente de 
Essa ideia é radicalizada pelo novo consenso, pois se por um lado ninguém nega que exista algum grau de inércia na inflação, por outro, ao impor a existência de inércia completa, qualquer choque adverso - independentemente do estágio inflacionário em que a economia se encontra -, tal como quebra de safras e choque no preço do petróleo resultaria em maiores taxas de inflação. Após esse ter se dissipado completamente, a taxa de inflação se estabilizaria em um nível permanentemente mais elevado que o inicial, exceto se fosse compensado por um choque negativo de igual magnitude (SERRANO, 2006, p. 3). Isso posto, descaracteriza-se qualquer possibilidade de escolha (trade-off) política entre inflação e desemprego. Ao contrário, não resta outra escolha política a não ser aquela de permanente atenção para a hiperinflação iminente.

Segundo Serrano (2006, p. 5), o resultado, acima descrito, muda radicalmente se "[...] admit that indexation is partial $(<1)$ even if by just a little", ou seja, se quebrarmos a restrição de inércia completa, supondo inércia parcial. Nesse caso, um choque de demanda se dissiparia com o tempo. Isso porque o aumento no nível de preços seria parcialmente repassado período a período até que se dissipasse completamente. Ou seja, se se aceita que a inércia é < 1, há uma mudança radical na análise, pois a cada período uma inflação menor é repassada. Uma explicação razoável para a existência de inércia parcial pode ser encontrada em Setterfield (2007). Esse autor argumenta que o poder de barganha de firmas e trabalhadores é desigual, uma vez que as primeiras têm maior poder de ditar salários ante os trabalhadores. ${ }^{29}$ Diante de um choque de demanda, o repasse para os preços seria apenas parcial, já que há:

[...] incomplete indexation [...] explained by incomplete bargaining power of workers vis a vis firms", o que muda radicalmente os resultados propostos pelo novo consenso já que "incomplete indexation by workers plays an important role in expunging from our model the notion of a supply-determined equilibrium rate of (un)employment that is invariant with respect to demand conditions (SETTERFIELD, 2007, p. 5).

Assumir inércia parcial implica que o resultado do aumento na oferta monetária (ou queda na taxa de juros) que aumentasse a demanda

realimentação, indica o grau de automatismo da inflação crônica, isto é, em que fração a inflação de um período se transmite ao período seguinte. A não ser em processos explosivos de hiperinflação, é de se supor normalmente que $0<\mathrm{b}<1$ [inércia parcial]".

29 Esse argumento é frequente na literatura pós-keynesiana, sendo considerado por alguns até como um dos axiomas de funcionamento das economias monetárias de produção (conceito utilizado por Setterfield (2007): o poder de decisão na economia monetária não é distribuído de forma igualitária entre os agentes. As firmas têm iniciativa tanto no processo produtivo e no mercado de trabalho quanto na decisão de investimento. Essa assimetria pode se traduzir em diferença nas barganhas salariais. Ver, por exemplo, Carvalho (1992). 
agregada e reduzisse o hiato do produto, seria o aumento da inflação e não a aceleração da mesma. De outra forma, se a autoridade monetária aumentasse permanente e crescentemente a taxa de expansão monetária, reduzindo período após período o hiato do produto, isso sim poderia gerar aceleração da inflação. Segundo Serrano (2006, p. 7), "[...] a inflação [no caso de inércia parcial, mantendo as demais hipóteses do modelo] é o resultado do excesso de demanda e a aceleração da inflação é função do aumento no excesso de demanda".

O baixo risco de haver uma hiperinflação ou aceleração da inflação pode ser mais reduzido ainda se quebrarmos a segunda hipótese, qual seja, a de que o produto é determinado pelo lado da oferta. Se, como propôs Keynes (1982) na Teoria Geral, a demanda agregada não possui um papel passivo na determinação do produto, ou seja, se a própria trajetória do produto potencial responde às variações do hiato do produto, a ideia de que as economias estão permanentemente sujeitas a hiperinflações se torna ainda mais improvável, mesmo se mantivermos a primeira hipótese (full-inertia).

Desse modo, se o produto potencial responde à demanda agregada, o aumento dessa, ao provocar o aumento da própria capacidade produtiva, via gastos que ampliam a capacidade (investimento), reduzem a pressão sobre a inflação, de tal modo que a aceleração inflacionária seria não factível ou seria meramente um fenômeno passageiro, ainda que se mantivesse válida a hipótese de completa inércia dos preços. Em outras palavras, políticas de expansão na demanda agregada reduzem no primeiro momento o hiato do produto, no entanto os estímulos à demanda agregada podem aumentar a eficiência marginal do capital (pois aumenta a receita esperada dos empresários) viabilizando novos projetos de investimento que criam capacidade produtiva, de tal modo que a pressão de demanda sobre os preços resultante de "excesso de demanda" é descomprimida, já que o gap do produto volta a aumentar.

Resta fazer algumas observações a respeito da terceira hipótese, qual seja a de que ao longo do tempo, choques de oferta positivos e negativos tendem a se autoanular, a despeito do modelo teórico dar grande importância aos choques de oferta - por alterarem os preços relativos - na explicação da dinâmica inflacionária, principalmente a partir dos anos 70. Na adoção prática, os choques de oferta são incluídos na equação de Phillips apenas como um componente estocástico. Isso implica na ideia de que no longo prazo o "vilão" da inflação ainda são as pressões de demanda agregada, já que choques diversos, tais como quebras de safras, cartelização ou outros choques de custos, ao se auto-eliminarem, são incapazes de afetar permanentemente a inflação.

Em temos de política econômica, a adoção dessa hipótese significa que o único meio consistente de conter processos inflacionários persisten- 
tes é comprimindo a demanda agregada, via taxa de juros. Note que a "via única” tanto para identificar a causa principal de processos inflacionários - excesso de demanda - como para conter tais processos - compressão da demanda -, resulta da imposição, conforme descrito acima, das hipóteses adotadas sobre a tendência do produto, da neutralidade da moeda e do insignificante papel dos choques no longo prazo. Como resultado, a adoção de políticas de altas taxas de juros seria o remédio, ainda que a suposta relação unívoca, estável e, portanto, previsível da transmissão dos juros para a demanda agregada seja passível de questionamentos. ${ }^{30}$

Por fim, o modelo padrão que serve de fundamentação para o regime de metas de inflação especifica uma regra reativa de juros, ou de política monetária, formulada endogenamente através das curvas IS e de Phillips (SVENSSON, 1997; BALL, 1997; BOGDANSKI et al.,2000). Tal regra deriva de uma regra do tipo regra de Taylor ${ }^{31}$ e seu objetivo seria anunciar uma resposta da taxa de juros aos desvios da inflação (especialmente nos modelos de metas inflacionárias). Na prática não existe o anúncio de uma regra reativa de juros. O que existe é uma meta para a inflação e a manipulação dos juros é utilizada para que a meta seja cumprida.

\section{Considerações Finais}

Procurou-se, ao longo deste trabalho, mostrar que a dinâmica inflacionária do modelo hoje conhecido por New Consensus Economics pode ser compreendida a partir de três hipóteses centrais, quais sejam (I) a inflação decorre do excesso de demanda agregada para além daquela sancionada pelas condições de oferta; (II) a taxa de juros é uma variável central neste modelo já que ao influenciar o investimento e assim, a demanda agregada, é a variável de controle inflacionário; (III) no longo prazo, existe uma taxa natural de desemprego que não acelera a inflação (NAIRU) para a qual a economia gravita. Essa é independente das condições de demanda, o que justifica o formato vertical da curva de Phillips no longo prazo.

Mais especificamente, analisamos as hipóteses subjacentes a uma das equações fundamentais da racionalização do modelo do New Consensus: a curva de Phillips. As imposições feitas aos parâmetros da curva de Phillips e as hipóteses a respeito da determinação do produto no longo prazo são,

30 Tais como a existência de defasagens, bem como a relação própria entre a taxa selic e os componentes da demanda agregada.

31 Segundo o BBC (2000, p. 96) uma regra de juros pode ser estabelecida de inúmeras formas diferentes. Não necessariamente o estabelecimento da regra reativa de juros deve seguir a formulação original de Taylor, em que a regra de juros poderia ter os objetivos simultâneos de controle inflacionário mais uma meta de produto. 
em larga medida, responsáveis pela suposta necessidade de constante vigília ao iminente risco de hiperinflação. Em outras palavras, a imposição de inércia inflacionária completa - primeira hipótese -, associada ao papel passivo da demanda em afetar o produto - segunda hipótese -, tornam as políticas de estímulos à demanda agregada indesejáveis, não somente por serem incapazes de afetar a trajetória de longo prazo do produto, mas por implicarem, necessariamente, na convivência com inflação mais elevada. O abandono da primeira hipótese conduz a resultados diferentes. Nesse caso, somente a aceleração da redução do gap do produto poderia implicar em aceleração da inflação. De outro modo, choques temporários ou constantes se dissipariam com o tempo, isso porque o aumento no nível de preços seria repassado apenas parcialmente período a período até que se dissipasse completamente.

Resultado ainda mais radical seria obtido se considerarmos que a demanda é relevante na determinação da trajetória de longo prazo do produto. Ou seja, o abandono da segunda hipótese, supondo, alternativamente, que o aumento na demanda agregada, ao aumentar a eficiência marginal do capital estimula novos investimentos, ampliando a capacidade produtiva, nos leva a concluir que a pressão de demanda sobre a inflação é muito reduzida, mesmo supondo inércia completa dos preços.

O terceiro e último elemento que foi passível de crítica se refere à inclusão de choques de oferta como aleatórios e, portanto, autoanuláveis com o tempo, a despeito da importância que os choques de oferta teriam na explicação de processos inflacionários. Isso posto, a dinâmica da inflação continua a ser explicada, como fora, historicamente, desde a primeira formulação da curva de Phillips, por pressões de demanda.

As imposições criadas ao funcionamento do mundo real expressos pela equação de Phillips levam a uma única via possível para a política econômica, qual seja o controle inflacionário, quer seja pela incapacidade da demanda em afetar o produto, quer seja porque a estabilidade de preços aumentaria a eficiência econômica, estimulando novos investimentos e o crescimento. Demovidas tais imposições, é possível que a política monetária ativa tenha papel fundamental na determinação do nível de atividade, tanto no curto quanto no longo prazo.

\section{Referências}

ARESTIS, P.; SAWYER, M. Inflation Targeting: A Critical Appraisal. Working Paper. The Levy Economics Institute of Bord Colleg, September, 2003.

BALL, L. (1997). Efficient rules for monetary policy. NBER working paper series, n. 5952, Mar/1997.

BARBOSA, E. S. O princípio de Say como critério de ortodoxia econômica. Dissertação 
(Mestrado em economia) - Departamento de Economia, Universidade Estadual de Brasília, Brasília/DF, 1990. 239f.

BARRO, R. J.; GORDON, D. B. Rules, discretion and reputation in a model of monetary policy. NBER working paper series, n. 1079, Feb/1983.

BBC (Boletim do Banco Central), Relatório de Inflação. Março, 2000.

BERNANKE, B. S.; MISHKIN, F. S.; LAUBACH, T.; POSEN, A. S. Inflation Targeting: lessons from the international experience. Princeton: Princeton University Press, 2001.

BERNANKE, B. S.; MISHKIN, F.S. Inflation targeting: a new framework for Monetary Policy? The Journal of Economic Perspectives, Vol. 11, n.2, Spring, p. 97-116, 1997.

BLINDER, A. S. The fall and rise of Keynesian economics. Economic Record, 1988, p.109-133.

BOGDANSKY, J.; TOMBINI, A. A.; WERLANG, S. R. Implementing inflation targeting in Brazil. Working Paper Series, Banco Central do Brasil, n. 01, julho/2000.

CAMPÊLO, A. K.; CRIBARI-NETO, F. Inflation inertia and inliers: the case of Brasil. Revista Brasileira de Economia, vol. 57, n. 4, Rio de Janeiro, Oct./Dec. p. 713-739, 2003.

CARVALHO, F. C. Moeda, Produção e Acumulação: Uma Perspectiva Pós-Keynesiana. In: Silva, M. L. F., Moeda e Produção: Teorias Comparadas. Editora Universidade de Brasília, Brasília, 1992.

CLARIDA, R.; GALI, J.; GERTLER, M. The Science of Monetary Policy: a new keynesian perspective. NBER Working Paper. Cambridge: National Bureau of Economic Research, n. 7147, maio/1999.

FRIEDMAN, M. Capitalism 8 Freedom: a leading economist's view of the proper role of competitive capitalism. Chicago: The University of Chicago Press, 1963. 202p.

. O papel da política monetária. In: SHAPIRO, E. (Org.) Análise macroeconômica: Leituras Selecionadas. São Paulo: Atlas, 1978, p. 417-433.

GORDON, D. What is new-Keynesian economics? Journal of Economic Literature. v. 28, sep. 1990. p. 1115-1171.

HADJIMICHALAKIS, M. G. Modern macroeconomics: an intermediate text Macroeconomics; Prentice-Hall, 1982.

KEYNES, J. M. A teoria geral do emprego, do juro e da moeda. tradução de Mário R. da Cruz; revisão técnica de Cláudio R. Contador. São Paulo: Atlas, 1982. 328p.

KLAMER, A. Conversas com economistas: os novos economistas clássicos e seus opositores falam sobre a atual controvérsia em macroeconomia. São Paulo: Pioneira/ed. Universidade de São Paulo, 1988. 271p.

KRIESLER, P.; LAVOIE, M. The new view on Monetary policy: The new consensus and its post-keynesian critique. Working Paper, n. 05-01. Research on banking international and national systems or networks University of Ottawa, 2005. < http://aix1.uottawa. $\mathrm{ca} / \sim$ robinson $>$.

LE HERON, E. A New Consensus on Monetary Policy? Brazilian Journal of Political Economy, Rio de Janeiro, v. 23. n. 4 (92), out.-dez./2003.

LOPES, F. L. Inflação inercial, hiperinflação e desinflação: notas e conjecturas. Revista de Economia Política. v. 5, n. 2, p. 135-151, abr.-jul./1985. 
MANKIW, N. G.; ROMER, D. (eds.) New Keynesian economics. v. 1, Introduction. Cambridge, MIT Press., 1989.

MANKIW, N. G. Recent development in macroeconomics: a very quick refresher course; comments. Journal of money, credit, and banking. Aug, 20 (3) ABI/INFORM Global, 1988, p.436-449.

MEYER. L. H. Does money matter? Federal Reserve Bank of St. Louis Review, v. 83, n. 5, Sept.-Oct., p. 1-15, 2001.

MISHKIN, F. S. Inflation Targeting in Emerging Market Countries. National Bureau of Economic Research, Working Paper 7618, Mar., 2000.

ROMER, D. Keynesian Macroeconomics without the LM curve. National Bureau of Economic Research, Cambridge, Jan., 2000.

. The new Keynesian synthesis. Journal of economic perspectives. v. 7, n.1, Symposium on Keynesian economics today, 1993, p.5-22.

SERRANO, F. Mind the gap: hysteresis, inflation dynamics and the sraffian supermultiplier. Second preliminary draft for discussion purposes. Mimeo. October, 2006.

SETTERFIELD, M. Is Inflation Targeting Inimical to Employment? In: the Meetings of the Eastern Economic Association. New York, Feb., 2007.

SIMONSEN, M. H. Inflação: gradualismo x tratamento de choque. Apec Editora, Rio de Janeiro, 1970. 215p.

SNOWDON, B.; VANE, W. R. Modern macroeconomics. Cheltenham UK Northampton, MA/ USA: Edward Elgar, 2005. 807p.

SVENSSON, L. E. O. Inflation forecast targeting: implementing and monitoring inflation targets. European Economic Review, 41, p. 1111-1146, 1997.

. Inflation targeting as a monetary policy rule. Seminar Paper, n. 646, Conference on Monetary Policy Rules, Stockholm, Jun. 1998, p. 12-13.

TAYLOR, J. B. A Core of Practical Macroeconomics. American Economic Review, v. 87, n. 2, May, p. 233-35, 1997.

. Teaching modern macroeconomics at the principles level. The American Economic Review. v. 90, n. 2, May, p. 90-94, 2000.

Recebido em: 22/07/2008.

Aceito em: 26/09/2008. 